\title{
O pulsar do centro da terra: interpretação do apoio zapatista à candidatura presidencial
}

\author{
Bruno Perozzi da Silveira \\ Universidade Estadual Paulista, Faculdade de Ciências e Letras, Programa \\ de Pós-Graduação em Educação Escolar, Araraquara, SP, Brasil (UNESP)
}

\section{O pulsar do centro da terra: interpretação do apoio zapatista à candidatura presidencial}

Resumo: Neste trabalho é realizada uma interpretação de um fato político ocorrido entre 2016 e 2017: o anúncio da candidatura de uma representante indígena, que pertence ao Congresso Nacional Indígena, e que tem o apoio dos povos zapatista e do próprio EZLN, para o pleito federal mexicano de 2018. Tal fato político é interpretado frente ao histórico de construção da autonomia pelos zapatistas mexicanos. Ao longo da década de 1990 e 2000, os zapatistas criaram autonomia territorial, bem como formas de organização local e regional (assembleias populares, caracóis, Juntas de buen gobierno etc). Assim, questiona-se: frente à centralidade da construção de autonomia nas práticas zapatistas, o que representa o apoio a participação na política institucional? Parte-se de autores que interpretam a contemporaneidade e principalmente as grandes transformações ocorridas no âmbito político, econômico e social da segunda metade do século XX em diante. Dessa forma, a interpretação de textos de Claus Offe servirá para a compreensão da crise do welfare state e do próprio Estado Nacional, frente ao processo de globalização e retomada do liberalismo econômico. Jürgen Habermas e Zygmunt Bauman foram as bases para a compreensão da crise política que é resultado de todo esse processo. Após essa qualificação teórica, analisa-se o contexto mexicano: a ascensão de governos neoliberais a partir da década de 1980 e o levante zapatista na década de 1990. Por fim, analisa-se o comunicado do CNI publicado no site Enlace Zapatista, no dia 14 de outubro de 2016, em que se propõe uma consulta popular sobre uma candidatura que represente o Congresso Nacional Indígena (CNI) e os zapatistas, bem como a escolha de Maria de Jesus Patricio, também denominada como Marichuy.

Palavras-chave: Política. Crise. Neozapatismo. Autonomia.

\section{The Pulse at the Center of the Earth: An interpretation of Zapatista support for a presidential} candidate

Abstract: This study interprets a political event that occurred between 2016 and 2017: the announcement of the candidacy of an indigenous representative from the National Indigenous Congress, and who had the support of the Zapatist peoples and from the Zapatist National Liberation Army (EZLIN), in Mexico's federal elections in 2018. This political fact is interpreted in relation to the history of construction of autonomy by the Mexican Zapatistas. During the 1990s and 2000, the Zapatistas created territorial autonomy, as well as forms of local and regional organizations (including popular assemblies, caracóis, Juntas de buen gobierno etc). The paper thus questions: considering the centrality of the construction of autonomy in Zapatist practices, what does the support for the participation in institutional politics represent? It begins by looking at authors who interpret contemporary issues and mainly the broad political, economic and social transformations since the second half of the twentieth century. The interpretation of texts by Claus Offe helps to understand the crisis of the welfare state and of the national state, in relation to globalization and the revival of economic liberalism. Jürgen Habermas and Zygmunt Bauman help understand the political crisis that is the result of this entire process. After this theoretical qualification, the Mexican context is analyzed: the rise of neoliberal governments since the 1980s and the Zapatista revolt of the 1990s. It finally analyzes the communication of the National Indigenous Congress that was published on the website Enlace Zapatista, on October 14, 2016, which proposed a popular plebiscite about a candidacy that would represent the National Indigenous Congress and the Zapatistas, as well as the choice of Maria de Jesus Patricio, also known as Marichuy. Keywords: Politics. Crisis. Neozapatism. Autonomy.

Recebido em 15.05.2017. Aprovado em 05.09.2017. Revisado em 30.11.2017.

C O(s) Autor(es). 2018 Acesso Aberto Esta obra está licenciada sob os termos da Licença Creative Commons Atribuição-NãoComercial 4.0 Internacional (https://creativecommons.org/licenses/bync/4.0/deed.pt_BR), que permite copiar, distribuir e reproduzir em qualquer meio, bem como adaptar, transformar e criar a partir deste material, desde que para fins não comerciais, e que você forneça o devido crédito aos autores e a fonte, insira um link para a Licença Creative Commons e indique se mudanças foram feitas. 


\section{Introdução}

Este trabalho surgiu da inquietação perante o anúncio do apoio dos zapatistas a uma candidatura ao pleito federal mexicano. Tal inquietação decorreu das posturas, sempre apresentadas pelos neozapatistas mexicanos, de defesa da autonomia política, territorial e educacional dos povos originários. Para buscar a compreensão deste fato político, iniciaremos por uma breve contextualização, tendo como pauta central o processo de crise das instituições políticas modernas, a contextualização histórica e política, será realizada no esteio das reflexões de autores contemporâneos como Clauss Offe, Jürgen Habermas e Zygmunt Bauman. Isto feito, o enfoque será dado ao contexto específico mexicano, bem como a emergência de formas de resistência ao neoliberalismo e à globalização, promovida pelos povos originários representados pelo Exército Zapatista de Libertação Nacional (EZLN). Com esta base teórica e contextual, teremos mais elementos para compreender os motivos do apoio zapatista à candidatura da indígena Marichuy, e buscaremos elementos presentes em dois comunicados, publicados no site Enlace Zapatista, para entender as perspectivas decorrentes deste apoio.

\section{A crise das instituições políticas no capitalismo avançado}

O século XX é marcado por profundas rupturas paradigmáticas. É um século que nasce em crise e em que as novas crises proliferam.

O conflituoso século XIX alimentou uma crença: o progresso levaria inevitável e progressivamente à diminuição das desigualdades, à pacificação total. A irrupção das tensões na Europa estilhaçou essa crença e, no recém-nascido século XX, o continente se afundou em um conflito generalizado. A primeira guerra mundial assombrou os mais pessimistas com seus números em mortandade, com a utilização das tecnologias mais avançadas para a guerra (como o avião, o tanque de guerra, a metralhadora) e com o uso da ciência como morte - nas nuvens de gás venenoso, nas bombas que caiam dos aviões. Esses aspectos deram início a um período de violência e de crises. Esse assombro viria a se repetir, anos mais tarde, marcando quase toda a metade do século.

A Segunda Guerra Mundial foi ainda mais ampla e violenta, suas raízes ainda estavam fincadas na Primeira Guerra. A ascensão de Estados totalitários, como resposta às sanções impostas aos perdedores da primeira guerra, trouxe à tona um nacionalismo que não prescindia do viés democrático e republicano. $\mathrm{O}$ nacionalismo nazista ou fascista, se ancorava na crise econômica e sob o ranço da vingança, com populações empobrecidas e famintas, para as quais a eloquência dos líderes, em sua ferocidade, agia como placebo.

O fim da Segunda Guerra Mundial em 1945, com a vitória dos aliados, dos países capitalistas mais avançados, marca o início de um ciclo de reestruturação econômica e política. A necessidade de reconstrução da Europa e os ecos da crise superprodutiva de 1929 traziam um novo significado ao Estado Nacional. Desde o início do século XX, o Estado inglês já trabalhava na implementação de medidas assistenciais. As lutas da classe trabalhadora no século precedente impulsionaram políticas de bem-estar social. No entanto, apenas nas décadas de 1930 e 1940 o Estado passa a intervir de forma mais direta na distribuição de bens, em políticas de garantia de cidadania e ampliando a rede de serviços sociais. Nos Estados Unidos, com a grave depressão econômica pós 1929, o governo Roosvelt implementa uma série de políticas assistenciais, concessões de crédito, financiamentos de grandes obras públicas, dentre outras ações, em um grande plano conhecido como New Deal.

As bases teóricas do estado do bem-estar social foram ancoradas principalmente sobre as teorias democráticas europeias, entre as quais se destaca a de Stuart Mill, e de modo mais direto, a obra de John Maynard Keynes cujo livro Teoria geral do emprego, do juro e da moeda, de 1936, torna-se a pedra angular na construção dos estados assistencialistas.

O Estado do bem-estar social aparece como solução neste período, não apenas para essa reconstrução, mas também como maneira de enfrentar o movimento de trabalhadores que lutavam por melhores condições de vida e como uma medida para o desenvolvimento de uma nova ordem econômica mundial diante do bloco socialista. ${ }^{1}$

No entanto, apesar dos avanços no campo da cidadania e da previdência, as políticas de intervenção estatal começam a apresentar sinais de desgaste a partir do final da década de 1960, principalmente em razão da dificuldade de equilíbrio orçamentário. Ou seja, frente às enormes responsabilidades sociais assumidas pelos Estados, ocorre o aumento da dívida pública, e consequente, crise fiscal, crescimento inflacionário e instabilidade social. Desde a década de 1940, havia contundentes críticas ao Estado Social por parte de alguns teóricos, dentre os quais se destaca Friedrich von Hayek, os quais defendiam o retorno do livre-mercado criticando a miragem de justiça social (HAYEK, 1985) do Estado previdenciário.

No entanto, o aspecto administrativo-econômico não é o único na crise do Estado do bem-estar social. Essa crise expõe as tensões permanentes no processo de formação dos Estados Nacionais a partir do século XIX. O 
cientista social alemão Claus Offe, em um ensaio intitulado A democracia contra o Estado do bem-estar? (1995), elenca três bases da relação entre cidadãos e autoridade estatal: o Estado de direito, ou seja, o aspecto liberal do Estado moderno, uma resposta institucional enquanto garantia legal da liberdade privada e corporativa perante a autoridade estatal; a democracia representativa, na qual o Estado moderno pauta sua legitimidade, principalmente por meio dos direitos políticos; e as garantias civis do Estado do bem-estar, que intervém na garantia dos direitos sociais e na busca do pleno emprego. Mais do que elencar esses três aspectos, o autor problematiza a viabilidade de um sistema político construído sobre essas bases, apresentando as tensões entre tais elementos, como as origens da crise da arquitetura das relações estado-mercado-sociedade civil.

Offe (1995, p. 271) parte de uma profícua discussão da ciência política do século XX, sobre o "problema global das tensões potenciais inerentes a esse conjunto de três componentes institucionais". Ao centrar a discussão sobre as tensões entre liberalismo e Estado do bem-estar, afirma que

[...] no início dos anos 80, uma grande parte do discurso sobre os problemas e desenvolvimentos futuros do Estado do bem-estar focalizava o alegado antagonismo entre o aspecto de garantia civil coletiva do Estado (isto é, do Estado do bem-estar) e os aspectos liberais do Estado (isto é, suas garantias de propriedade privada, de relações de mercado contratuais e, conseqüentemente, de uma economia capitalista). Esses discursos, em que prevalecem as perspectivas filosóficas e políticas da direita neoconservadora e liberal, postula que o Estado do bem-estar se tornou um peso muito grande para a economia, cujo crescimento potencial e a competitividade estariam, conseqüentemente, sofrendo os custos e a rigidez dos excessivos impostos sobre o mercado pelas condições de organizadas pelo Estado do bem-estar e pela organização da previdência social. (OFFE, 1995, p. 272, grifos do autor).

Além desse aspecto centralmente econômico, Offe chama a atenção para outro aspecto político, a crise da unidade entre democracia e liberalismo.

Em um artigo, A democracia partidária competitiva e o 'Welfare State' keynesiano: fatores de estabilidade e desorganização (1984), o sociólogo discorre sobre uma característica que viria a se tornar a base das instituições políticas no século XX: a construção do Estado Nacional sobre as bases da democracia plena e do capitalismo (partindo da proposta de livre-mercado). Assim, os partidos de massas, que ascendem na Europa após a Primeira Guerra, e o welfare state keynesiano, pós Segunda Guerra mundial, se unem e colocam em coexistência a democracia e o capitalismo.

A democracia partidária competitiva atenuaria as tensões sociais, respondendo aos interesses do mercado e fazendo com que exista estabilidade na construção dos Estados Nacionais ocidentais. No entanto, após a década de 1970, ocorre um rápido declínio do sistema de partidos de massa. Offe destaca alguns motivos para essa crise de representatividade: o surgimento de novos movimentos sociais, que não se identificam ou não se sentem representados nelo sistema partidário de massas.

Por outro lado, o corporativismo acaba por desparlamentarizar a política e a "concomitante substituição das formas de representação territorial, pelas formas funcionais" (OFFE, 1984, p. 357) e, por fim, emerge a possibilidade da criação de caminhos alternativos à competição partidária, pautada na repressão e na gradual transformação da democracia em autoritarismo. Fato percentível na América Latina a partir das décadas de 1950-1960.

Offe argumenta que as características intrínsecas do welfare state acabam por exauri-lo, tanto pelo peso econômico das políticas assistenciais, quanto pela crise de representatividade. Assim, a década de 1970 marca o início de um novo ciclo econômico e político em âmbito global - ciclo que se mantem em pleno desenvolvimento até hoje -, construído com o suporte da globalização, enquanto amplo processo de internacionalização da economia, ruptura das fronteiras comerciais, centralidade da economia no capital financeiro, bem como a retomada das teses do livre mercado, agora para além das fronteiras nacionais, naquilo que se convencionou chamar de neoliberalismo.

Da crise dos elementos centrais dos Estados Nacionais do pós-guerra emergiram diversas outras crises. No ensaio Em busca da política (2000), Bauman nos lembra que a palavra

[...] 'crise' foi cunhada para designar o momento de tomar decisões. Etimologicamente, tem muito mais a ver com o termo criterion - princípio que usamos para tomar a decisão certa - do que com a família de palavras associadas a 'desastre' ou 'catástrofe' na qual costumamos localizá-la hoje. [...] Para colocar a coisa de maneira mais precisa, ainda pensamos atualmente em crise como um momento de mudança decisiva para melhor ou pior, mas não mais como o momento em que decisões sensatas podem ser tomadas com autoconfiança para garantir uma virada para melhor. Em estado de crise, não sabemos que rumo as coisas irão tomar; em estado de crise as coisas escapam ao controle, não temos domínio sobre os acontecimentos [...]. (BAUMAN, 2000, p. 144-145). 
Partindo dessa pressuposição, podemos constatar que o fim do século XX inaugura uma grande crise, que atinge frontalmente os aspectos políticos, econômicos, sociais, morais e culturais da modernidade. O livro Em busca da política (BAUMAN, 2000) traz uma discussão contemporânea de suma importância, não somente por seu caráter diagnóstico, mas pelo cotejamento de obras contemporâneas, que nos permite compreender as profundas transformações pelas quais passamos pelo menos desde a década de 1970, com a crise do welfare state nos países de capitalismo avançado. Poderíamos afirmar, a partir do título, que se trata de uma obra especificamente sobre política. No entanto, é possível perceber que o texto apresenta uma análise mais vertical, profunda. Bauman não reflete apenas sobre a crise das instituições políticas, mas amplia seu raio de interpretação e parte dos aspectos morais, éticos, estéticos, econômicos e políticos. Se é possível tomarmos uma expressão ou palavra central do diagnóstico da contemporaneidade do autor, essa palavra é insegurança.

O ponto de partida é a afirmação de que a globalização e a financeirização da economia iniciada nos anos 1970 acabaram por relativizar boa parte do poder das instituições políticas. O poder flui e flutua fora da política. Esse processo leva a uma profunda insegurança com relação à política e ao campo de ação da política, ou seja, ao espaço público.

Sob essa nova configuração, o capital flui livremente sobre as fronteiras políticas. No entanto, a política e a ação política se mantêm locais. Essa perda de poder dos agentes e instituições políticas leva a uma profunda apatia política do eleitorado e do corpo dos cidadãos. Bauman é incisivo em seu diagnóstico: se a contemporaneidade é fundada sobre múltiplas inseguranças e os meios coletivos de gerar segurança parecem estagnados, a política perde seus meios de ação.

A insegurança sobre como ganhar a vida, somada à ausência de um agente confiável capaz de tornar essa situação menos insegura ou que sirva pelo menos de canal para reivindicações de uma segurança maior, é um duro golpe no coração mesmo da política de vida. (BAUMAN, 2000, p. 28).

E não apenas os indivíduos em geral se encontram atônitos, até mesmo os agentes políticos, que por pressuposto, deveriam garantir os espaços públicos e os direitos às populações, integram o coro neoliberal, apresentando o livre mercado global como condição natural, necessária e imprescindível, e não como opção política palpável, modificável. O discurso neoliberal forja um realismo, um alarmismo difícil de combater. Justamente por desestabilizar e despotencializar as instituições políticas é mais difícil de combatê-lo. Os governos nacionais acabam ficando de mãos atadas frente aos acordos que liberam as multinacionais, frente ao trânsito de capital financeiro fluído.

Desse modo, essa grande transformação estrutural e geopolítica incorre em um ataque direto às instituições que fundam a modernidade e a contemporaneidade: o Estado-nação, a família, os sindicatos, o emprego, dentre outras. Tudo é relativizado em um "reinado absoluto da flexibilidade" (BAUMAN, 2000, p. 34).

A fluidez do capital, sob as fronteiras nacionais, tem como agentes ativos as organizações supranacionais, como o Fundo Monetário Internacional (FMI) e o Banco Mundial (BM). Criados ainda nos primeiros anos do pós-guerra, o FMI e o BM agem como facilitadores e mediadores das políticas de livre-mercado. Impõem exigências aos Estados para a liberação de crédito. Os países em desenvolvimento sofrem diretamente com as determinações do mercado global, dentre os países latino-americanos, o México foi um laboratório de políticas neoliberais durante os anos de 1990.

\section{Neoliberalismo no México}

No que concerne à relação entre os países centrais do capitalismo e os periféricos, a proposição dos requisitos econômicos passa por uma imposição política sobre os governos dos últimos. As adequações às políticas de abertura do mercado, de diminuição da taxação sobre importação e exportação, são colocadas como pré-requisitos para a integração na economia globalizada, e também para a concessão de crédito e empréstimos.

O neoliberalismo dificilmente poderia deixar de impor tais requisitos. A diferença é que o faz não somente no campo das relações internacionais, mas também sobre a direção e conteúdo das políticas e instituições internas. Por isso, se integram em normas e regras, que auspiciam determinadas políticas e eliminam os conteúdos em outros modelos, inspirados em planejamentos ideológicos racionalizadores. O estabelecimento dessas normas e suas consequências justificam alterações profundas na vida dos países, particularmente na divisão do trabalho entre o Estado e o mercado ou entre os poderes dos governos nacionais e os da globalização. Consequentemente, o neoliberalismo e a globalização postulam critérios que devem satis- 
fazer os governos - singularmente os do Terceiro Mundo -, quase sempre com escassa ou nula anuência dos cidadãos afetados. (IBARRA, 2011, p. 2).

Na América Latina, isso se dá de forma contundente. Após a Segunda Guerra Mundial, os países latinoamericanos, em geral, passam a desenvolver suas economias nacionais, principalmente por meio de um processo de industrialização e nacionalização das riquezas. A partir da década de 1950, frente à agudização da Guerra Fria e, em 1959, ao êxito da Revolução Cubana, a influência norte-americana sobre o continente, especialmente na América Central e América do Sul, se torna intervenção de fato. Os golpes militares e civismilitares, que tomam 10 países, são orquestrados, financiados ou influenciados pelo capital internacional, centralmente pelos norte-americanos. As ditaduras mantêm os Estados Nacionais fortes nos países latino-americanos, no entanto, as economias se tornam dependentes do BM e do FMI, bem como, de modo mais direto, das relações com os Estados Unidos (EUA), e há um vertiginoso crescimento das dívidas externas.

Profundamente ligado à economia norte-americana, o México transita por pelo menos três modelos econômicos ao longo do século XX:

\begin{abstract}
El modelo agrarioexportador, vigente de la consolidación del capitalismo a mitad del siglo XIX, hasta la gran depresión de los años treinta; 2. El modelo de sustitución de importaciones, que surgió en el periodo de entreguerras, se consolidó durante la Segunda Guerra Mundial (1939-1945) y entró en crisis en la década de los setenta; 3. El modelo neoliberal de los años ochenta (1982) a los primeros años del Siglo XXI. Grosso modo, cada modelo económico se acompañó de una forma particular de Estado: El modelo agrario-exportador se escoltó del Estado 'guardián'; el sustitutivo de importaciones, del Estado interventor; el modelo neoliberal, del Estado ‘mínimo’ o neoliberal. (SALAZAR, 2004).
\end{abstract}

Ou seja, a partir da década de 1980, o modelo neoliberal é colocado como alternativa ao Estado interventor mexicano, que havia progressivamente aumentado o investimento nas políticas sociais ao logo da década de 1970, gerando um profundo déficit fiscal².

Assim, frente à profunda crise econômica do início dos anos oitenta, assume a presidência da república o Partido Revolucionário Institucional (PRI), em dezembro de 1982, Miguel de la Madrid Hurtado (1982-1988), o qual implementou o Programa Inmediato de Reordenación Económica (PIRE), com medidas de austeridade, corte de investimentos sociais (ou gastos sociais, na nomenclatura neoliberal), como tentativa de redução da dívida pública e do déficit fiscal. No entanto, essas medidas acabaram por retrair a produção, aumentar o desemprego, tendo consequências diretas sobre as populações mais pobres. Em 1987, a inflação chegou a $167 \%$, enquanto o PIB registrava um índice negativo de $-3,4 \%$.

Nesse contexto, o secretário da Secretaría de Programación y Presupuesto ${ }^{3}$, Carlos Salinas de Gortari, propõe, em conjunto com a Secretaria de la Hacienda, o Programa de Aliento y Crecimiento (PAC), que depois se converte no Pacto de Estabilidad Y Crecimiento Económico, no fim de 1987. Esses programas de adequação aos requisitos do BM e do FMI, reconduzem o México ao crescimento econômico, apesar da ampliação da dívida externa. A retomada da economia leva Carlos Salinas (PRI) à presidência em 1988.

A continuidade dos programas de Salinas acelera a economia mexicana, diminui a inflação e abre a possibilidade de renegociação da dívida externa. Salinas, frente ao êxito econômico, começa a aplicar as ações de seu liberalismo social.

En el gobierno de Carlos Salinas, se consolidó la reforma del Estado con la venta de grandes empresas paraestatales, el saneamiento de las finanzas públicas (al pasar del déficit al superávit fiscal), el control de la inflación, así como las modificaciones constitucionales de los artículos 3, 27 y 130. Las reformas constitucionales dejaron de lado las principales fuentes de la legitimidad estatal nutridas en el nacionalismo revolucionario. Para subsanar y apuntalar al nuevo proyecto, Salinas presentó en marzo de 1992 en la Asamblea Extraordinaria del PRI al 'Liberalismo Social' como cobijo y sustento ideológico de la reforma del Estado. (SALAZAR, 2004).

As condições de renegociação da dívida externa aceitas por Salinas atingiam duramente os setores mais pobres da sociedade mexicana. As consequências do aumento de importações e diminuição dos subsídios para agricultura familiar e para a produção agrícola de exportação, levaram a um aumento da desigualdade social, que atingiu duramente as populações indígenas de diversas etnias. Quando, nos últimos dias de dezembro de 1993, Salinas assinou o Tratado Norte-Americano de Livre Comércio (NAFTA), as imposições da economia internacional - via renegociação de dívida externa e concessão de empréstimos - passaram a determinar as políticas nacionais mexicanas de modo mais direto e contundente. 
No mundo todo, em meados dos anos noventa, despontavam movimentos antiglobalização. Da Coreia do Sul a Seattle ${ }^{4}$, as políticas neoliberais passam a ser questionadas. No México o levante do Exército Zapatista de Libertação Nacional demonstra esse questionamento. Apesar de a assinatura do NAFTA ser o gatilho para o levante, a organização dos indígenas do sul e sudoeste mexicano já vinha ocorrendo desde o início das políticas neoliberais nos anos 1980. Assim, os neozapatistas tinham como pauta central a oposição às onerações impostas pela economia internacional, principalmente aquelas que atingiam frontalmente os direitos dos indígenas. Frente às sanções impostas pelo Estado mexicano, os zapatistas lutaram pelo reconhecimento da pluralidade étnica, pela garantia dos direitos indígenas (principalmente pela demarcação de terras) e pela autonomia organizacional e política.

\section{Exército Zapatista de Libertação Nacional: breve histórico}

O modelo neoliberal de globalização impôs ao bloco latino-americano uma realidade de pobreza e opressão e, por seu caráter hegemônico, promoveu, além de uma ampla dominação econômica, também uma profunda imposição cultural. Os resultados econômicos para os indígenas e camponeses de Chiapas, província do sudeste mexicano, foram desastrosos. O preço do café, principal produto da região, despencou acarretando o aumento da pobreza de sua população. Porém, uma das piores consequências foi a revisão do artigo 27 da Constituição (ORNELAS, 2005). Esse artigo, fruto da Revolução Agrária Mexicana de 1910, possibilitava a distribuição de terras e a demarcação dos chamados ejidos: propriedades agrárias coletivas, pertencentes ao Estado, para o uso das comunidades indígenas. Essas propriedades sociais foram alvo das reformas a partir de 1992, com a desaceleração da distribuição de terras e a abertura da possibilidade de venda e privatização (RAMÍREZ GARCÍA, 2000).

No dia em que o acordo do NAFTA passou a vigorar, os indígenas de diversas etnias do sudeste mexicano organizaram um levante armado. Os povos chiapanecos demonstraram a sua insatisfação com os rumos da política mexicana. Partindo da região montanhosa de Selva Lacandona, esses guerrilheiros, que se autodenominaram Exército Zapatista de Libertação Nacional (EZLN), ocuparam o controle de sete municípios do estado de Chiapas.

Já em janeiro de 1994, era anunciada em comunicados ${ }^{5}$ a amplitude das lutas zapatistas. Após as primeiras batalhas, em 12 de janeiro de 1994, o EZLN opta pelo caminho pacífico. Apesar de não deporem as armas, os zapatistas começam a construção de seus projetos de afirmação cultural, educação e diálogo contra as reformas neoliberais, sendo rapidamente implantados nos municípios tomados. Uma palavra é central em suas proposições: Autonomia, a construção de uma autonomia política, organizacional e territorial.

Ao longo de cinco anos, após o levante armado de 1994, houve inúmeras tentativas de diálogo entre governo federal e EZLN, não apenas no que concerne aos territórios, mas também à deposição de armas da guerrilha. A pauta central dos zapatistas era a autonomia política de seus territórios. Mesmo que na primeira declaração, logo após o levante, não se encontre a palavra autonomia, essa pauta vai tomando centralidade com o passar dos anos. Em 1996, o governo federal, sob a presidência de Ernesto Zedillo, se reúne com representantes zapatistas na aldeia de San Andrés Larráinzar, e por meio de uma comissão denominada Comisión de Concordia y Pacificación (COCOPA), assina um tratado que previa uma reforma constitucional na qual seriam garantidos os direitos étnicos e culturais indígenas, o reconhecimento dos territórios e da autonomia zapatista. No entanto, esse tratado conhecido como Acordo de San Andrés jamais foi colocado em prática.

Em 2000, o presidente Vicente Fox, do Partido de Ação Nacional (PAN), vence, após setenta anos, o Partido Revolucionário Institucional (PRI) e, apesar da tentativa de diálogo, principalmente por parte dos zapatistas $^{6}$, o governo de Fox não aprovou as reformas necessárias, intensificando as ações e perseguições contra os zapatistas. Assim, os zapatistas começaram uma construção mais intensa da organização autônoma das comunidades, em outras palavras, assumiram a tarefa de implantar o Acordo de San Andrés, à revelia do governo federal. Nesse período, surgem os chamados Caracóis Zapatistas que, mais do que sedes administrativas e de governo de territórios zapatistas - em conjunto com as Juntas de Bom Governo ${ }^{7}$-, atuavam como porta-vozes e interlocutores de um diálogo cada vez mais aberto com outros setores descontentes da sociedade mexicana e de outros países.

Após anos de tentativas sucessivas de diálogo e de conflitos entre os guerrilheiros e os soldados do governo, em 2005, na Sexta Declaração da Selva Lacandona, com conquistas por parte dos zapatistas, o subcomandante Marcos ${ }^{8}$ anuncia a deposição de armas do EZLN (RAMÍREZ GARCIAA, 2000). Essa atitude demonstra a escolha pelos zapatistas do caminho da educação, da formação e do diálogo (BARONNET, 2012), representando, de certo modo, uma ampliação da proposta de organização autônoma, abarcando não apenas a questão territorial e política, mas também de um ponto de vista educacional ${ }^{9}$. 


\section{Um pulsar que vem do centro da terra: a candidatura indígena}

Retomando as perspectivas de Bauman (2000), há uma profunda crise do Estado Nacional frente às práticas internacionalizadas do capital. No México esse processo é evidente. A ascensão de governos com características neoliberais a partir de 1982 (Miguel de La Madrid, Salinas e Ernesto Zedillo), bem como a continuidade dessa política por Fox e Felipe Calderón, ambos do partido oposicionista PAN (Partido da Ação Nacional) e, por fim, o retorno do PRI ao governo com Enrique Peña Nieto desde 2012, coloca a necessidade de construção da autonomia por parte dos zapatistas na defesa dos direitos indígenas. Essa busca por autonomia se ampliou desde o início de os anos 1990, como vemos nos Municípios Autônomos Rebeldes Zapatistas (MAREZ), que ocupam boa parte da província de Chiapas, no sudoeste mexicano, se autodeclaram autônomos politicamente e territorialmente.

Justamente por essas características intrínsecas ao movimento zapatista, o comunicado de 14 de outubro de 2016 causou espanto, porque previa o apoio dos zapatistas e do próprio EZLN à candidatura ao pleito federal mexicano de 2018.

Após o percurso teórico e contextual desenvolvido até agora, podemos refinar os questionamentos iniciais: frente ao processo de crise da representatividade e do próprio Estado Nacional, o que representa essa candidatura? O histórico do movimento zapatista sempre se pautou pela autonomia frente à política institucional, frente ao Mal Gobierno, o que mudou? O que pretendem os zapatistas?

Para encontrar algumas respostas, partiremos da interpretação do comunicado do $5^{\circ}$ Congresso Nacional Indígena. Esse comunicado ficou disponível a partir de 14 de outubro de 2016, no site zapatista Enlace Zapatista (CNI; EZLN, 2016). O comunicado foi feito durante o Quinto Congresso Nacional Indígena $(\mathrm{CNI})^{10}$, que ocorreu entre os dias 10 e 13 de outubro na cidade de San Cristóbal de las Casas em Chiapas. O título do comunicado faz um apelo ao coração vibrante da Mãe-terra e, desse modo, a todos os mexicanos, ao remeter à primeira estrofe do hino nacional mexicano: Que Retiemble en sus Centros la Tierra.

Direcionado aos pueblos del mundo e a los medios libres de comunicación, o comunicado que encerrou reafirma o posicionamiento do CNI (bem como dos próprios zapatistas), abajo y a la izquierda, que somos anticapitalistas y que se ha llegado el tiempo de los pueblos, de hacer vibrar este pais con el latir ancestral del corazón de nuestra madre tierra, trazendo à tona o histórico de exploração e opressão sobre os povos indíge-

O modelo neoliberal de globalização impôs ao bloco latino-americano uma realidade de pobreza e opressão e, por seu caráter hegemônico, promoveu, além de uma ampla dominação econômica, também uma profunda imposição cultural. Os resultados econômicos para os indígenas e camponeses de Chiapas, província do sudeste mexicano, foram desastrosos. nas desde a colonização, en 524 años en que los poderosos iniciaron una guerra que tiene como fin exterminar a los que de la tierra somos.

Após esse introito, o comunicado pontua 27 denúncias de diversas naturezas, que marcam um aprofundamento da tensão entre governo, empresariado e indígenas. Essa "[...] tempestad y ofensiva capitalista que no cesa sino que se vuelve cada día más agresiva y se ha convertido en una amenaza civilizatoria no sólo para los pueblos indígenas y campesinos sino para los pueblos de las ciudades [...]" (CNI; EZLN, 2016). É interessante notar que as denúncias são localizadas não pelas províncias, mas pelos povos que habitam os territórios, assim, desde o Pueblo Coca, que teve suas terras comunitárias invadidas por empresários, passando pelo povo Zoque de Oaxaca y Chiapas, cujo território se encontra ameaçado pela mineração, até a memória dos 43 estudantes da escola normal rural Raúl Isidro Burgos, de Ayotzinapa ${ }^{11}$.

De modo geral, essas denúncias giram em torno da expropriação de territórios, por empresas agrícolas e de mineração. No entanto, também abarcam os impactos da construção de gasodutos, aeroportos e rodovias sobre as comunidades indígenas. As acusações são direcionadas a "los malos gobiernos, sus empresas y su delincuencia organizada" (CNI; EZLN, 2016).

Assim, nota-se que há uma reafirmação da oposição dos grupos étnicos reunidos no CNI, não apenas às empresas nacionais e internacionais que invadem ou conseguem a concessão de territórios (muitas vezes ancestrais e/ou sagrados), mas também, de modo recorrente, aos diferentes níveis de governo mexicano, aos 
malos gobiernos - essa expressão é repetida 14 vezes ao longo do texto. Além disso, o governo é também acusado de sequestrar e manter presos centenas de indígenas (CNI; EZLN, 2016).

O comunicado traz o mesmo tom dos documentos zapatistas anteriores, pontuando de maneira direta a importância da territorialidade indígena e a necessidade da unidade para a resistência frente aos avanços do capital, assim como é recorrente - não apenas nos comunicados, mas também nos sites e redes socais zapatistas $^{12}$ - denúncias de casos locais, de repressão, ameaça e violências cometidas por parte dos agentes do governo e de grupos ligados aos empresários. Mas é importante notar que a posição crítica perante o governo mexicano se mantém. Isso porque os zapatistas identificam que as ações governamentais acabam se colocando contra os interesses dos indígenas e a favor dos interesses dos empresários e grupos empresariais nacionais e internacionais.

Frente à quantidade de denúncias de violências, invasões, sequestros e assassinatos cometidos por empresas, fazendeiros e pelo governo, o CNI chega a algumas considerações após os 27 pontos de denúncias, reiterando a postura de resistência e de rebeldia.

A questão central dessas considerações é a construção da autonomia. Frente ao avanço do neoliberalismo e aos ataques às culturas e territórios indígenas, que se sucedem governo após governo desde os anos 1980, o CNI pontua a necessidade da continuidade da construção de assembleias locais, conselhos indígenas, Juntas del Buen Gobierno, Caracóis, mais do que isso, reafirma a construção da autonomia interna, em sistemas educativos, formação bilíngue, meios de difusão e comunicação alternativos, dentre tantas ações para a autonomia propostas e realizadas nos territórios rebeldes.

Para defender lo que somos, nuestro caminar y aprendizaje se han consolidado en el fortalecimiento en los espacios colectivos para tomar decisiones, recurriendo a recursos jurídicos nacionales e internacionales, acciones de resistencia civil pacífica, haciendo a un lado los partidos políticos que sólo han generado muerte, corrupción y compra de dignidades, se han hecho alianzas con diversos sectores de la sociedad civil, haciendo medios propios de comunicación, policías comunitarias y autodefensas, asambleas y concejos populares, cooperativas, el ejercicio y defensa de la medicina tradicional, el ejercicio y defensa de la agricultura tradicional y ecológica, los rituales y ceremonias propias para pagar a la madre tierra y seguir caminando con ella y en ella, la siembra y defensa de las semillas nativas, foros, campañas de difusión y actividades político culturales. (CNI; EZLN, 2016).

No fim do documento, o CNI propõe a criação de uma assembleia permanente de consulta popular para decidir a candidatura de seus representantes e de maneira geral do CNI. Essa consulta deveria ser realizada até os primeiros meses de 2017 e abarcará 43 povos originários de 523 comunidades de 25 estados. Se positivo o resultado, deverá ser formado um Consejo Indigena de Gobierno (CGI), com uma mulher indígena indicada à disputa pela presidência.

Considerando que la ofensiva en contra de los pueblos no cesará sino que pretenden hacerla crecer hasta haber acabado con el último rastro de lo que somos como pueblos del campo y la ciudad, portadores de profundos descontentos que brotan también en nuevas, diversas y creativas formas de resistencias y de rebeldías es que este Quinto Congreso Nacional Indígena determinó iniciar una consulta en cada uno de nuestros pueblos para desmontar desde abajo el poder que arriba nos imponen y que nos ofrece un panorama de muerte, violencia, despojo y destrucción. Ante todo lo anterior, nos declaramos en asamblea permanente y consultaremos en cada una de nuestras geografías, territorios y rumbos el acuerdo de este Quinto CNI para nombrar un concejo indígena de gobierno cuya palabra sea materializada por una mujer indígena, delegada del CNI como candidata independiente que contienda a nombre del Congreso Nacional Indígena y el Ejército Zapatista de Liberación Nacional en el proceso electoral del año 2018 para la presidencia de este país. (CNI; EZLN, 2016).

Nesse trecho é possível perceber que a proposição da candidatura se ancora sobre pelo menos dois pressupostos: primeiro, por uma necessidade reativa, como forma de resistência e desmonte do poder tal como vem sendo exercido. Ou seja, a construção da autonomia local e regional, que vem sendo realizada nos territórios rebeldes, tem sido constantemente impedida, interrompida ou destruída pela ação do mal gobierno, seja diretamente por meio das ações militares e policiais, seja politicamente por meio do desmonte da legislação territorial indígena, ou pela política econômica de abertura ao capital nacional e internacional de exploração das reservas e territórios mexicanos. O outro pressuposto é a consulta direta aos povos. Ou seja, o respeito à vontade popular, que é representada não apenas pela consulta, em sua amplitude, mas pela proposição de uma representação feminina e indígena, que se candidataria à presidência no pleito de 2018 , de forma independente 
- uma vez que os "partidos políticos que sólo han generado muerte, corrupción y compra de dignidades" (CNI; EZLN, 2016) - e em nome do CNI, com apoio expresso do EZLN e dos povos zapatistas.

Ratificamos que nuestra lucha no es por el poder, no lo buscamos; sino que llamaremos a los pueblos originarios y a la sociedad civil a organizarnos para detener esta destrucción, fortalecernos en nuestras resistencias y rebeldías, es decir en la defensa de la vida de cada persona, cada familia, colectivo, comunidad o barrio. De construir la paz y la justicia rehilándonos desde abajo, desde donde somos lo que somos. Es el tiempo de la dignidad rebelde, de construir una nueva nación por y para todas y todos, de fortalecer el poder de abajo y a la izquierda anticapitalista, de que paguen los culpables por el dolor de los pueblos de este México multicolor. (CNI; EZLN, 2016).

O trecho destacado acima encerra o comunicado e, de certa forma, busca justificar a opção pelo pleito. Afirma que a candidatura não representa uma luta por poder, mas uma forma de resistência ativa, sobre os avanços de políticas que atingem de maneira direta as diversas etnias mexicanas. Conclama uma construção a partir de baixo, a qual a candidata, se eleita, comporia e responderia.

Os questionamentos que emergem do apoio dos zapatistas à formação do Conselho Nacional Indígena (CGI) foram respondidos em diversas ocasiões, talvez o documento mais exemplar, no qual são descritos os motivos do apoio zapatistas, seja um comunicado publicado ainda no dia 17 de novembro de 2016, que tem por título: Uma história para tratar de entender, assinado pelos subcomandantes insurgentes Moisés e Galeano (2016).

Este comunicado é uma narrativa, nas palavras do sub Galeano, que inicia com uma dura crítica aos meios de comunicação, aos intelectuais e à própria esquerda mexicana, pelas acusações de incoerência da candidatura com os ideais e práticas zapatistas. Galeano parte de uma frase, retirada da Sexta Declaração da Selva Lacandona e que foi utilizada para ilustrar o descompasso da proposta atual e da prática e discurso histórico dos zapatistas: "Nuestros sueños no caben en sus urnas" (MOISÉS; GALEANO, 2016). A esta provocação, responde Galeano:

Nosotros, nosotras, como zapatistas que somos la suscribimos entonces... y ahora. Tiene la virtud de decir mucho con pocas palabras (un arte ahora olvidado). Pero, desde este lado del pasamontaña, desde nuestro ser lo que somos, agregamos: ‘tampoco nuestras pesadillas'. (MOISÉS; GALEANO, 2016).

A resposta de Galeano aponta para o tom que seguirá no comunicado, algo que já evidenciamos na análise do comunicado de 14 de outubro de 2016, ou seja, o princípio reativo da candidatura. Se os sonhos não cabem nas urnas, tampouco deve-se permitir que os pesadelos as ocupem.

Feita essa crítica inicial, o narrador preocupa-se em esclarecer uma confusão: a atribuição da candidatura aos zapatistas.

Sí, la propuesta inicial y original es nuestra, del ezetaelene. Nosotras, nosotros, se la hicimos saber a las delegadas y delegados al Quinto Congreso del Congreso Nacional Indígena. Esto sucedió los días 9, 10, 11 y 13 de octubre del año 2016, en la sede del CIDECI-Unitierra, en San Cristóbal de Las Casas, Chiapas, México. En esas fechas hubo delegadas y delegados de colectivos, organizaciones, barrios, tribus, naciones y pueblos originarios de las lenguas amuzgo, binni-zaá, chinanteco, chol, coca, náyeri, cuicateco, kumiai, lacandón, matlazinca, maya, mayo, mazahua, mazateco, mixe, mixteco, nahua, ñahñu, ñathô, popoluca, purépecha, rarámuri, tlapaneco, tojolabal, totonaco, triqui, tzeltal, tzotzil, wixárika, yaqui, zoque, y chontal. El día 13 de octubre del 2016, la plenaria de ese Quinto congreso del CNI decidió hacer suya la propuesta y someterla a una consulta entre quienes lo integran. El día 14 de octubre del 2016, en horas de la mañana, el CNI y el EZLN hicieron pública esa decisión en el documento llamado 'Que retiemble en sus centros la tierra'. (MOISÉS; GALEANO, 2016, grifos dos autores).

Mas, apesar de a ideia ter sido proposição do EZLN, em específico, de Galeano e Moises, a candidatura pertence ao CNI, que, segundo suas próprias palavras, é maior que o EZLN.

No, ni el EZLN como organización, ni ninguna, ninguno de sus integrantes, va a participar por un "cargo de elección popular" en el proceso electoral del 2018.

No, el EZLN no se va a convertir en un partido político.

No, el EZLN no va a presentar a una mujer indígena zapatista como candidata a la presidencia de la República en el año del 2018. 
No, el EZLN no "ha dado un giro" de los grados que sean, ni seguirá su lucha por la vía electoral institucional. Entonces ¿el EZLN no va a postular a una indígena zapatista para presidenta de la República? ¿No van a participar directamente en las elecciones de 2018? No.

(MOISÉS; GALEANO, 2016).

Mas um questionamento ainda se mantém: por que o EZLN proporia tal candidatura durante o Congresso? Esperam, os zapatistas, alcançar o cargo máximo do executivo, fazendo uma transformação, em contrário aos seus discursos, desde arriba?

Sub Galeano busca responder a estas questões e elenca alguns motivos que levaram a proposição, bem como as possibilidades que podem decorrer da participação do processo eleitoral. Centralmente podemos afirmar que o intuito é levar la rabia y el dolor dos povos originários (e dos não-indígenas de abajo) ao conhecimento de todos. Frente ao rápido avanço das políticas neoliberais, que agridem frontalmente os povos indígenas, Galeano toma a palavra no V Congresso Nacional Indígena (ainda em outubro de 2016) propõe em nome dos zapatistas:

\begin{abstract}
Nosotros les venimos a proponer otra cosa: estamos golpeados, con muertes, desapariciones, secuestros, encarcelamientos, despojos, injusticias, territorios enteros destruidos y otros en vías de extinción. Estamos acorralados, sin esperanzas, sin fuerzas, sin apoyos, débiles, agonizantes. Para los políticos y los medios, aunque sean de izquierda o progresistas, no existimos. Así que nosotros, nosotras, zapatistas, pensamos que es el momento de pasar a la ofensiva. Llegó la hora del contra ataque. Y hay que empezar golpeando uno de los corazones del sistema: la política de arriba. Por eso les proponemos que el CNI forme una Junta de Gobierno Indígena (así se llamaba en nuestra propuesta original; ya en asamblea, y a propuesta de una delegación indígena magonista de Oaxaca, pasó a llamarse 'Concejo Indígena de Gobierno'), un colectivo, formado por delegados del CNI, que aspire a gobernar el país. Y que se presente a las elecciones presidenciales del 2018 con una mujer indígena del CNI como candidata independiente. (MOISÉS; GALEANO, 2016).
\end{abstract}

Ou seja, é possível inferir, a partir da leitura dos comunicados (tanto o do CNI, quanto o do EZLN) que é a revolta, a irrupção da crítica que mobiliza a candidatura, é a união dos que estão abajo que dá sentido além da política institucional, os subcomandantes Galeano e Moises deixam claro que, apesar de serem os proponentes, atuarão como apoiadores e não contradirão os princípios de autonomia de seus territórios.

\title{
Conclusões
}

Segundo o Mapa da Desigualdade Mundial, apresentado pela ONG britânica Oxfam no início de 2017, apenas 1\% da população global concentra em mãos mais riqueza que os 99\% restantes, além disso, ao longo dos próximos 20 anos, 500 pessoas transferirão mais de US\$ 2,1 trilhões para seus herdeiros - soma mais alta que o PIB da Índia, que tem 1,2 bilhão de habitantes. A renda dos 10\% mais pobres aumentou cerca de US\$ 65 entre 1988 e 2011, enquanto a do 1\% mais ricos aumentou cerca de US\$11.800, ou seja, 182 vezes mais. Uma constatação chama a atenção: os oito homens mais ricos do mundo detêm a mesma riqueza que 3,6 bilhões de pessoas, ou seja, a metade da população mundial (BETTO, 2017).

Ao pensarmos sobre o aprofundamento do abismo de desigualdade nos países periféricos, o caso mexicano é exemplar. O começo do século XX foi marcado pela Revolução Mexicana, que foi determinante na promulgação da Constituição de 1917. Essa Constituição foi a primeira (antes mesmo da Constituição de Weimar) a garantir os direitos sociais. Além disso, garantiu os direitos e territórios as populações indígenas mexicanas (que correspondem a $15,1 \%$ da população segundo dados de 2014 do CEPAL).

No entanto, nas últimas décadas, os direitos conquistados estão sendo reduzidos, não apenas pela ação política direta dos governos neoliberais das décadas de 1980, 1990 e 2000, mas também pelas políticas econômicas e imposições da economia internacional, que colocam o México como economia dependente (principalmente com relação aos vizinhos do Norte), aumentando em larga escala as desigualdades.

O México é um dos países latino-americanos que menos investe em proteção social, direcionando apenas 7,4\% do PIB. Em dados da Comissão Econômica para a América Latina e Caribe (CEPAL), o México tem um dos piores salários mínimos da América Latina, tanto que o valor está abaixo da linha da pobreza per capita, tendo uma desvalorização de 77\% nos últimos 35 anos, sendo de apenas 129 dólares mensais no final de 2016 (7 DATOS..., 2005).

Frente a esses preocupantes dados, que nos dão uma dimensão do abismo de desigualdade social que continua se abrindo e se aprofundando nas últimas décadas, fica mais fácil compreender a postura dos zapatistas e do CNI. 
Bauman (2000), dentre outros autores, discorre em suas obras sobre o conceito de crise, definindo-a como um momento de compreensão das restrições e, mais do que isso, é um momento de ação, de mudança decisiva para melhor ou pior.

Podemos afirmar, partindo das ideias dos autores aqui expostos, que passamos por uma ampla e profunda crise nos âmbitos político, econômico, ético e social. Essa crise, apesar de seu caráter global, tem consequências diretas nos países mais pobres e naqueles em desenvolvimento. Quando olhamos para dentro desses países, percebemos que as populações mais pobres (e as chamadas minorias) sofrem de modo mais contundente com essa ampla crise sistêmica.

Nesse contexto, é possível compreender o caráter reativo das posturas zapatistas, e em específico da proposição da candidatura. Frente a um avanço irrefreável da crise sobre os povos indígenas, os zapatistas e a CNI se levantam, seja em suas formas organizacionais locais, seja ao buscarem voz, solidariedade e espaço para suas demandas na disputa do pleito em 2018.

Se a crise é, como nos ensinam Baumam (2000) e Habermas (1980), um momento de tomar decisões e agir, o CNI toma para si a responsabilidade. Ainda no final de dezembro de 2016 e início de 2017, ocorreu a segunda parte do V Congresso Nacional Indígena, no mesmo local da primeira parte (San Cristobal de las Casas), na assembleia final ficaram acordadas as diretrizes para a constituição do Conselho de Governo Indígena. Em 27 e 28 de maio o conselho é criado por deliberação da Assembleia do CNI, constituído por 71 conselheiros, de etnias indígenas de todas os Estados mexicanos. No mesmo dia, foi definida a porta-voz e pré-candidata independente à presidência do México: María de Jesús Patrício Martínez, conhecida como Marichuy. Da etnia nahua, de Tuxpan, no Estado de Jalisco, referência na medicina tradicional e na defesa dos direitos indígenas.

Ao propor a candidatura para as eleições de 2018, na figura emblemática da mulher indígena, o CNI coloca em pauta as consequências de décadas de política econômica de crise sobre os povos de abajo, levantam a bandeira das minorias oprimidas, massacradas e pauperizadas, fazem com que a fluidez plácida do capital estremeça, de um tremor ancestral e sagrado, multicolor, desde o centro de la tierra.

Desde a criação do conselho e da escolha de Marichuy, tem se formado uma grande campanha, com o apoio de diversos segmentos da sociedade mexicana e de outros países. Um milhão de assinaturas deverão ser coletadas para a inscrição para o pleito. O caminho ainda é longo até 2018, ao acompanhá-lo, ouviremos essas vozes, talvez nos identifiquemos com elas, mas, é certo, aprenderemos.

\section{Referências}

7 DATOS que muestran la desigualdad extrema en México. Forbes México. 24 jun. 2005. Disponível em: <http://www.forbes.com.mx /7-datos-que-muestran-la-desigualdad-extrema-en-mexico/\#gs.eg9eOkU>. Acesso em: 15 mar. 2017.

A QUARTA guerra mundial (humanocracia). Youtube, 13 jul. 2012. Disponível em: <https://youtu.be/F-QXn8IpBLg>. Acesso em: 15 mar. 2017.

BARONNET, B. Autonomia y Educación Indígena. Las escuelas zapatistas de la Selva Lacandona de Chiapas, México. Quito: AbyaYala, 2012.

BAUMAN, Z. Em busca da Politica. Rio de Janeiro: Zahar, 2000.

BETTO, frei. Cresce a desigualdade mundial. O Globo, 26 jan. 2017. Disponível em: $<$ http://oglobo.globo.com/economia/crescedesigualdade-mundial-20826853>. Acesso em: 15 mar. 2017.

CONGRESO NACIONAL INDÍGENA; EJÉRCITO ZAPATISTA DE LIBERACIÓN NACIONAL. Que retiemble en sus centros la tierra. Enlace Zapatista, Chiapas, 14 oct. 2016. Não paginado. Disponível em: <http://enlacezapatista.ezln.org.mx/2016/10/14/queretiemble-en-sus-centros-la-tierra/>. Acesso em: 15 mar. 2017.

HABERMAS, J. Um conceito científico-social de crise. In: Brasileiro, 1980.

HAYEK, F. A. von. A miragem da justiça social. São Paulo: Ed. Visão (UnB), 1985.

IBARRA, D. O neoliberalismo na América Latina. Revista de Economia Política, São Paulo, v. 31, n. 2, abr./jun. 2011. Disponível em: $<$ http://www.scielo.br/scielo.php?script=sci_arttext\&pid=S0101-31572011000200004>. Acesso em: 15 mar. 2017.

MOISÉS, Subcomandante; GALEANO, Subcomandante. Una historia para tratar de entender. Enlace Zapatista, México, 17 nov. 2016. Não paginado. Disponível em: <http:/enlacezapatista.ezln.org.mx/2016/11/17/una-historia-para-tratar-de-entender/>. Acesso em: 15 mar. 2017. OFFE, C. A democracia partidária competitiva e o "Welfare State" keynesiano: fatores de estabilidade e desorganização. In:

Problemas estruturais do Estado capitalista. Rio de Janeiro: Tempo Brasileiro, 1984. p. 356-386.

Capitalismo desorganizado. São Paulo: Brasiliense, 1995.

ORNELAS, R. A autonomia como eixo da resistência zapatista - Do levante armado ao nascimento dos Caracoles. In: CECEÑA, A. E. (Org.). Hegemonias e emancipações no século XXI. Buenos Aires: CLACSO, 2005. p. 129-167. 
RAMIREZ GARCIA, L. B. Chiapas e o Zapatismo: da humilhação à dignidade. 2000. Tese (Doutorado em Psicologia Escolar e do Desenvolvimento Humano) - Instituto de Psicologia, Universidade de São Paulo, São Paulo, 2000.

SALAZAR, F. Globalización y política neoliberal en México. El Cotidiano, México, v. 20, n. 126, jul./ago. 2004. Não paginado. Disponível em: <http://www.redalyc.org/pdf/325/32512604.pdf>. Acesso em: 15 mar. 2017.

\section{Notas}

1 Cabe pontuar que, enquanto nos países mais desenvolvidos do bloco capitalista as políticas do estado Social avançavam, nos países periféricos, como por exemplo os países latino-americanos, ascendiam diversas formas governamentais, muitas vezes regimes ditatoriais, impostos por golpes civis-militares.

2 O investimento em políticas sociais saltou de 22\% do PIB em 1970 para 44\% do PIB em 1982, ao mesmo tempo em que o déficit fiscal vai de $6 \%$ até $16 \%$ do PIB. (SALAZAR, 2004).

3 Criada em 1958 com onome de Secretaría de la Presidencia de la República, a Secretaría de Programación y Presupuesto, como foi chamada a partir de 1976, tem por função concentrar e articular o planejamento e estratégias entre os órgãos da administração pública federal. É ligada ao poder executivo e à secretária da Fazenda mexicana, sendo incorporada, em 1992, a esta última, que se tornou Secretaria de Hacienda y Crédito Público.

4 Há um interessante documentário norte-americano de 2003 sobre a extensão dos movimentos antiglobalização, chamado Aquarta guerra mundial. (A QUARTA..., 2012).

5 Os quais passaram a ser denominados como Declarações da Selva Lacandona.

6 Em 2001 a Marcha del color de la tierra, composta por 24 delegados zapatistas, viajou pelo país conquistando apoio popular e foi ouvida no congresso. Sua pauta principal foi o cumprimento do Acordo de San Andrés. No entanto, o resultado dessa pressão foi uma reforma agrária que não aplicava as principais demandas indígenas (RAMÍREZ GARCÍA, 2000).

7 Em 2005 as Juntas de Bom Governo foram estabelecidas para possibilitar a articulação da sociedade civil pró-zapatista e os municípios autônomos rebeldes zapatistas, funcionando como um território zapatista (MAREZ). Ver Ornelas (2005).

8 OSubcomandante Marcos é uma figura controversa dentro do levante zapatista. Isto pelo fato de que o governo mexicano o reconhece como sendo Rafael Sebastián Guillén Vicente, ex-aluno da Faculdade de Filosofia e Letras da Universidade Nacional Autônoma do México (UNAM) e professor da Universidade Autónoma Metropolitana (UAM), em Cidade do México, mas não há provas com relação a essa identificação, já que a figura do subcomandante Marcos aparece sempre mascarada, afirmando que não se trata de uma pessoa, mas de uma figura política que está sob o comando dos povos zapatistas. Assim, do ponto de vista dos zapatistas, o subcomandante Marcos não é uma pessoa específica, mas um ícone, um porta-voz, sem identidade pessoal, dos povos zapatistas. O Subcomandante Marcos se retirou da posição de porta-voz em 2007, reaparecendo na homenagem a José Luis Solís López, conhecido como Galeano (em homenagem ao uruguaio Eduardo Galeano), professor zapatista assassinado no dia dois de maio de 2014. Nesta homenagem, o subcomandante anunciou a morte de Marcos e o novo nome: subcomandante Galeano.

9 Os zapatistas iniciam a criação do Sistema Educativo Rebelde Autônomo Zapatista de Libertação Nacional (SERAZLN) a partir dos Acordos de San Andrés (firmados entre governo e FZLN), em 1996.

10 Entidade que reúne 66 grupos étnicos mexicanos.

11 No dia 31 de maio de 2013, estudantes da Escola Rural Raúl Isidro Burgos desapareceram após confronto com a polícia em uma manifestação na cidade de Iguala, na província de Ayotzinapa. Três dias depois, seus corpos foram encontrados, carbonizados. Investigações da Procuradoria Geral da República ligavam os assassinatos a grupos de narcotraficantes ligados a José Luis Abarca, prefeito de Iguala. O fato gerou grande comoção popular, e iniciou uma nova fase na organização dos zapatistas, que de certo modo, reverbera na proposta de candidatura.

12 Os zapatistas mantêm páginas na rede social Facebook e sites, como por exemplo: Enlace Zapatista (disponível em: <http:// enlacezapatista.ezln.org.mx/>. Acesso em: 15 mar. 2017). Durante o Quinto CNI foi deliberado a criação do seu site (disponível em: $<$ www.congresonacionalindigena.org.mx $>$.Acesso em: 15 mar. 2017).

\section{Bruno Perozzi da Silveira}

brunoperozzi@ibest.com.br

Mestrado em Educação Escolar pelo Programa de Pós-Graduação em Educação Escolar (PPGEE) da Faculdade de Ciências e Letras da Universidade Estadual Paulista (UNESP)

\section{UNESP}

Faculdade de Ciências e Letras (FCLAr)

Rod. Araraquara - Jaú, km 1 - Machados

Araraquara - São Paulo - Brasil

CEP: $14.800-901$ 